\title{
INSTRUCCIONES PARA LOS SUBDELEGADOS DE LA INTENDENCIA DE POTOSÍ REALIZADAS POR EL INTENDENTE JUAN DEL PINO MANRIQUE EN 1784
}

\author{
THE INSTRUCTIONS FOR POTOSÍ “SUBDELEGADOS” MADE BY \\ THE “INTENDENTE” JUAN DEL PINO MANRIQUE IN 1784
}

\author{
María Concepción Gavira Márquez*
}

\begin{abstract}
Este artículo contiene la transcripción de las instrucciones para los subdelegados de Potosí realizadas por el gobernador intendente Juan del Pino Manrique en 1784, precedida de un estudio que pretende contextualizar dichas instrucciones y su importancia en el ámbito andino del virreinato del Río de la Plata. Conocer las competencias de estos nuevos cargos permitirá evaluar la importancia y consecuencias de las reformas a nivel local y nacional. No existe duda de que los últimos cambios en la administración y gobierno de los territorios americanos fueron decisivos en los procesos de independencia y en la organización jurisdiccional de muchas de las nuevas repúblicas americanas.
\end{abstract}

Palabras claves: Subdelegados, Potosí, reformas borbónicas.

This work consists of the transcript of the instructions for Potosi "subdelegados" made by the "intendente" Juan del Pino Manrique in 1784. The instructions are preceded by a study that puts them in context and analyzes their importance for the Andean region of the Viceroyalty of the Rio de la Plata. The precise knowledge of the competences attached to these new positions allows us to evaluate the significance and the impact that the reforms implemented by the Bourbon monarchy had at the local and national level. There is no doubt that the changes introduced by these reforms in the administration and government of the American territories exerted a decisive influence on the processes of independence and jurisdictional organization of many of the new American republics. Key words: Potosí, Bourbon Reforms, bureaucracy.

El primer régimen de intendencia que se estableció en el continente americano fue en el virreinato del Río de la Plata con fecha de 1782. La premura en este virreinato fue producto de la situación de crisis y conflicto que la sublevación indígena había conseguido establecer en gran parte de su jurisdicción, especialmente en el Alto Perú. Este levantamiento indígena que se dio de manera simultánea en distintos lugares, tuvo uno de sus focos en Chayanta (Potosí) liderado por los hermanos Kataris, el cual extendiéndose por el altiplano terminó contactando con el movimiento de Tupac Amaru y alcanzando un importante impacto en ciudades como Oruro o La Paz. Una de las quejas de los indígenas sublevados fue la extorsión y abusos de los corregidores. La reforma administrativa a partir de la aplicación del régimen de intendencias contemplaba entre uno de sus objetivos acabar con la odiosa figura del corregidor de indios y sustituirla por los subdelegados.

La Real Ordenanza para el establecimiento e instrucción de intendentes de ejército y provincia en el Virreinato de Buenos Aires en 1782, conocida como la Real Ordenanza de Intendentes, fue aplicada durante el reinado de Carlos III. Según estudiosos como Mariluz Urquijo $(1995: 84)^{1}$, esta legislación es fiel reflejo del pensamiento ilustrado, evidenciando especialmente las respectivas funciones de la metrópoli y las colonias, y en consecuencia se manifiestan diferencias en el conjunto de disposiciones. En todo caso, el objetivo era potenciar el Estado aumentando a la vez sus recursos y para ello había que consolidar un buen cuerpo de funcionarios que fueran capaces de gestionar y aumentar la Real Hacienda. En esta política, los intendentes serían los hombres claves para conseguir esos objetivos ayudados por sus subordinados directos: Los subdelegados.

La bibliografía sobre la administración colonial en los territorios comprendidos en la jurisdicción territorial de la Audiencia de Charcas, hoy Bolivia, para este periodo no es muy extensa, se pueden señalar trabajos clásicos como el de Jon Lynch (1962) sobre el virreinato del Río de la Plata, y de los historiadores del derecho como Emilio Ravignani (1938), José M.

* Universidad Michoacana de San Nicolás de Hidalgo, Facultad de Historia, Morelia, México. Correo electrónico: conchagavira@ yahoo.es 
Mariluz Urquijo (1987; 1995), Ricardo Rees Jones (1992; 1995), Eduardo Martiré (2005) y Edberto Óscar Acevedo (1992) que han publicado diferentes estudios sobre las instituciones y autoridades de fines de la colonia. Sobre el espacio del Alto Perú o jurisdicción territorial de la Audiencia de Charcas son más escasos y destacan los trabajos centrados en Potosí, los cuales abordan la política borbónica y sus implicaciones en la minería, como ejemplo sirvan los trabajos de Enrique Tandeter (1992) y Rose Mari Buechler (1989). En definitiva, lo más frecuente ha sido abordar la figura de los intendentes y se ha marginado el papel y la importancia de los subdelegados.

Las instrucciones que presentamos a continuación no fueron las únicas que se dejaron de forma escrita a los subdelegados para ayudarles en las labores de gobierno en sus partidos. Para el virreinato del Río de la Plata, las primeras fueron las realizadas por el intendente presidente de la Audiencia de Charcas Ignacio Flores; sin embargo, Acevedo califica las del intendente de Potosí Joaquín Pino Manrique como el conjunto de instrucciones más detalladas (Acevedo 1992:119-122). Curiosamente en la Ordenanza General de Intendentes de 1803 se tenía contemplado un anexo que consistía en unas instrucciones para los subdelegados compuesto por 34 artículos que detallaban sus facultades y obligaciones como funcionarios, pero estas no se llegaron a aprobar (Rees 1995:181).

La Real Ordenanza de Intendentes fue modificada por Real Cédula del 5 de agosto de 1783, pero fueron tan solo 17 declaraciones para ajustarse mejor a la realidad ${ }^{2}$. Posteriormente fueron revisándose y realizándose algunas modificaciones que también fueron fruto de circunstancias determinantes como la muerte en 1787 de José de Gálvez y en 1788 de Carlos III, ambos personajes decisivos en la renovación de la administración y gobierno de la metrópoli y los territorios americanos; entre las reformas cabe destacar la supresión de las superintendencias que tantos conflictos creaban con los virreyes. Las diferentes posturas e informes sobre el nuevo régimen provocó que en 1802 Carlos IV convocara una Junta para perfeccionar y unificar las Ordenanzas (Las Ordenanzas de 1782 del Río de la Plata y la de 1786 de Nueva España) y fruto de estos trabajos fue la Ordenanza General de Intendentes que se aprobó en 1803, pero fue retirada en enero de 1804 sin que fuese aplicada (Rees 1995). Por tanto, fueron las Ordenanzas de 1782 con sus modificaciones las que regirían el virreinato del Río de la Plata hasta su independencia.

La Real Ordenanza de intendentes estableció la división del virreinato del Río de la Plata en ocho intendencias o provincias, y lo que antes considerábamos provincias tomaría el nombre de partidos, así quedaba definido muy bien en la primera ley dicha Ordenanza:

"A fin de que mi Real voluntad tenga su pronto y debido efecto mando se divida por ahora en ocho intendencias el distrito de aquel Virreinato y que en lo sucesivo se entienda por una sola provincia el territorio o demarcación de cada Intendencia con el nombre de la ciudad o villa que hubiese de ser su Capital y en que habrá de residir el Intendente, quedando las que en la actualidad se titulan provincias con la denominación de Partidos..." (San Martino 1995:135).

En el territorio bajo la jurisdicción de la Audiencia de Charcas, o también conocido como el Alto Perú, se crearon 5 intendencias o provincias: La Plata o Charcas, Potosí, Cochabamba, La Paz y Puno desde 1784 hasta 1796, en que pasó a formar parte del virreinato del Perú (Luque 1999).

El primer intendente de la provincia de Potosí fue Juan del Pino Manrique, el cual para regular el gobierno de su territorio creó estas instrucciones que presentamos basadas en la Real Ordenanzas de Intendentes del Río de la Plata de 1782 y de esta manera procuraba facilitar el gobierno de los subdelegados de su provincia. Estas instrucciones tienen fecha de enero de 1784, cuando ya Juan del Pino llevaba un año como intendente en Potosí. Los partidos sujetos a su gobierno eran cinco: Porco Chayanta, Chichas ${ }^{3}$, Lipez y Atacama, los mismos que antes eran nominados como corregimiento y tenían como representante de la administración colonial un corregidor.

En la ley novena de las Ordenanzas de Intendentes decía que "en los pueblos de indios que sean cabeceras de partido, y en que hubiese habido Teniente de Gobernador o corregidor... el intendente nombrará por el tiempo de su voluntad un subdelegado que lo ha de ser en las quatro causas..." (San Martino 1999:141). Estas mismas causas quedaron recogidas de manera explícita en las instrucciones que Juan del Pino dejaba por escrito 
a sus subdelegados: Policía, Hacienda, Exército, Justicia. Todos los subdelegados de la provincia de Potosí eran subdelegados de cuatro causas, aunque hay que decir que en el Alto Perú hubo subdelegados de dos causas (Hacienda y Guerra), en especial cuando se encontraban en ciudades de españoles con cabildo, como por ejemplo ocurría en Oruro ${ }^{4}$.

El primer intendente de Potosí era malagueño de origen, había estudiado derecho en Granada, y después de pasar a Madrid contactó y fue vinculado a la visita general del virreinato peruano de José Antonio Areche y Jorge Escobedo. Según Pedro de Angelis, fue considerado "como uno de los ministros más ilustrado de su época” (De Angelis 1836), destacándose su labor como fiscal de la Audiencia de Charcas. Fue nombrado en 1781 gobernador de Potosí después de que Jorge Escobedo tuviese que marchar a Lima a encargarse de la visita del virreinato peruano, y posteriormente se quedó en esta provincia como intendente. Como primer intendente de Potosí en 1783 tuvo que poner en práctica la nueva jurisdicción y funciones de su cargo. Entre sus obligaciones en este nuevo cargo se encontraba la de formar una matrícula de la población de sus partidos y comenzó a ejecutarla durante 1787 , dando cumplimiento a lo dispuesto en las Ordenanzas de Intendentes de 1782. Comenzó esta visita por el partido de Chayanta ${ }^{5}$ y desde allí decía el intendente que vio la necesidad de crear unas instrucciones para los alcaldes pedáneos ${ }^{6}$. Éste intendente, con formación en derecho, tenía una obsesión por reglamentar las competencias de cada una de las instituciones y los cargos administrativos coloniales, dejando muchas evidencias sobre el ejercicio de su cargo. La información de la visita a los diferentes partidos de la intendencia de Potosí fue publicada por primera vez en 1836 bajo el título Descripción de la villa de Potosí y de los partidos sujetos a su intendencia, en la colección de Pedro de Angelis y hoy la podemos consultar por internet en la página de la Biblioteca Virtual Miguel de Cervantes.

Los partidos que comprendían la intendencia de Potosí se distinguían por tener una mayoría de población indígena y en segundo lugar mestiza asentada en pueblos o doctrinas de indios. La descripción que daba Juan del Pino después de su visita a estos pueblos era muy deprimente:

"Lugares desolados sin orden ni formación; casa pajizas derramas por los campos; total abandono de estos; ríos sin puentes; caminos casi intransitables; ninguna comodidad para los viajes: distancias muy largas sin albergue, y gente sin cultura, es la fea imagen que presenta cada uno de estos países más o menos cercano o distante a los caminos reales o pueblos numerosos. En todos los partidos sólo se ven trazas y señales del gobierno despótico de los corregidores, atentos solo a hacer un comercio exclusivo a su utilidad..."7.

En su mayoría, salvo Atacama en la costa del actual Chile, eran poblaciones establecidas a gran altura en el altiplano andino con unas condiciones climáticas difíciles para los españoles, pero con el atractivo de las minas de plata. Partidos como Porco, Lipez, Chichas y Chayanta habían sido o eran a fines del siglo. XVIII centros mineros productores de plata más o menos importantes. En el caso de Atacama ya se destacaba la minería del cobre. Sin embargo, como indica el intendente, la provincia se encontraba falta de atenciones en caminos, puentes, albergues..., cuestiones pendientes y destacadas en las instrucciones de las Ordenanzas respecto del ramo de policía.

Pero antes de hacer referencia a las distintas competencias de estos nuevos funcionarios recogidas en las instrucciones, abordaremos algunas cuestiones importantes: ¿quién nombraba a los subdelegados y quiénes podían ser nombrados como subdelegados?

El nombramiento de estos cargos fue en un principio responsabilidad del intendente hasta la real orden de octubre de 1788. Esta ley estipulaba que los intendentes debían dar cuenta al virrey de los nombramientos para su aprobación, pero mientras llegaba la confirmación virreinal, se podían nombrar interinos. Los requisitos para ser nombrados eran un poco confusos, pues se requería personas hacendadas, es decir, con recursos, pero que estuvieran dispuestas a salir de su ambiente para ejercer un empleo sin sueldo. La dificultad radicaba, según los intendentes, en encontrar postulantes para un cargo sin sueldo y sin posibilidad de comerciar, tan solo tenían estipulado un 4\% del total de los tributos recogidos (Mariluz 1995). Estas condiciones eran incompatibles con el proyecto de implantar una burocracia eficaz, puesto que si no se remuneraba el empleo, era bastante probable que se utilizase el cargo con fines particulares. Sin duda la falta de sueldo reducía el número de postulantes, de tal 
forma que se terminó nombrando vecinos del mismo partido, como ocurrió frecuentemente. El aliciente y atractivo para ejercer este puesto dependía de la cantidad de población de los partidos y del monto de la tributación estipulada, del cual el $4 \%$ se quedaba el subdelegado, pero esta cantidad se reducía más porque tenía que separar el $1 \%$ para el cobrador; en Nueva España quedó establecido en el 6\% y se reducía al $5 \%{ }^{8}$. En el caso de los partidos de Chayanta y Porco que eran de población muy numerosa, el subdelegado obtenía una cantidad respetable. Por ejemplo, Pedro Francisco de Arizmendi ${ }^{9}$ que fue subdelegado de Porco y después de Chayanta tenía una ganancia de 2.089 pesos por el $3 \%$ del tributo de este último partido en 1797.

La duración del cargo fue motivo de modificaciones. En principio, no se estipuló una duración limitada del cargo, sino a voluntad del intendente, pero en 1792 una real orden determinó el ejercicio durante 5 años y posteriormente se decidió que fueran 6 años (Acevedo 1992:117). En algunos casos los subdelegados fueron rotando por los distintos partidos de la intendencia como el caso al que hicimos alusión de Pedro Francisco de Arizmendi que fue subdelegado de Porco en 1785 y después de Chayanta en 1791 o también el caso de Benito Antonio Goyena que fue de Atacama en 1790 y después en 1804 estaba como subdelegado de Chichas.

Las instrucciones se estructuran de manera sencilla, en principio tiene 10 artículos generales o preámbulo al igual que la Real Ordenanza que precedían las cuatro causas. La primera es la causa de Justicia que tiene 11 artículos, la segunda de Policía con 16, la tercera la causa de Hacienda que tiene 13 artículos y la última la causa de Guerra con un solo artículo. Termina la instrucción con un último artículo relativo al procedimiento administrativo.

La mayoría de las competencias de los subdelegados tiene un trasfondo económico, es decir, aunque se dividieran en las cuatro causas se advierte un objetivo final, aumentar los recursos que provenían de la actividad de los indígenas a través del fomento de la producción y de la fiscalidad. Sin duda la estrategia principal para ello era la información. Así en la instrucción número 3 se alude a los artículos 8, 9,10 y 11 de las Ordenanzas sobre la obligación de informar al intendente sobre las ciudades, villas, lugares y pueblos que hubiere en cada partido, "distinguiendo los que sean de españoles y los de meros indios" (ver $\mathrm{N}^{\mathrm{o}} 3$ de las
Instrucciones), así como las actividades y recursos naturales de la población de los distintos partidos.

Del preámbulo de las instrucciones cabe señalar el artículo número 6, el cual advierte que el subdelegado debe residir en el pueblo cabecera del partido; este hecho no siempre se cumplía y a veces los vecinos se quejaban de la ausencia de éstos cuando se les necesitaban y los perjuicios de ir a buscarlos hasta Potosí donde solían residir ${ }^{10}$. Pero lo más importante de esta misma instrucción es la prohibición de "repartir a los indios, españoles, mestizos y demás castas, efectos, frutos ni ganados alguno" (véase instrucción $\mathrm{N}^{\circ}$ 6). Ya hemos aludido a la queja y denuncias de muchos caciques indígenas por los abusos sobre el reparto de mercancías realizado por los corregidores a los indios ${ }^{11}$, que especialmente se intensificaron a partir de 1751 . La legalización del reparto de mercancías en ese año de 1751 representó el respaldo de la Corona a una práctica que venía realizándose desde el siglo anterior y que consistía en la distribución de mercancías entre la población indígena a precios generalmente más altos que los fijados en los mercados regionales. Esta medida tenía el objetivo de evitar los abusos, pero también permitía aplicar un impuesto sobre el monto de los productos repartidos. Sin embargo, este respaldo de la Corona provocó un aumento de los abusos de los corregidores (Golte 1980) ${ }^{12}$ que está relacionado con los levantamientos indígenas que se producían décadas antes de la sublevación de 1781 . Por ejemplo, Joaquín Alós, corregidor de Chayanta (corregimiento perteneciente a Potosí y donde se originó la sublevación katarista), tenía permitido un reparto de mercancías por valor de 92.665 pesos y el corregidor admitió haber repartido 109.000 pesos $^{13}$. Sin embargo, Tomás Katari denunciaba que los repartos del corregidor se aproximaban a los cuatrocientos mil pesos. Parece que además de Alós repartieron mercancías sus tenientes Luis Núñez y Lucas Villafañe (Lewin 1957:300).

Pero a pesar de todos los abusos y polémicas sobre el reparto de mercancías y su necesidad de prohibirlos, para apaciguar las protestas de los indígenas se añadió un polémico artículo en el que se admitía que: "de cuenta de su Real Hacienda se avíe a los naturales y demás necesitados y otras castas que no tengan medios ni proporciones para hacerlo por si mismos del hierro, aperos, mulas y otros útiles y necesarios a la industria y labranza dándoselos al fiado y los precios fijos que por solo costo y costas se regulen dando a estas anticipaciones el nombre 
de socorros" (Instrucción No 7). Esta especie de socorro, tal como se temía fue una fórmula para encubrir algunos repartos de mercancías por parte de algunos de los nuevos funcionarios ${ }^{14}$.

En estas instrucciones para los subdelegados de la provincia o intendencia de Potosí de 1784 no hay ninguna novedad o aporte añadido por el intendente Juan del Pino Manrique, tan solo se trata de sumar y recoger todas las disposiciones que contiene la Real Ordenanza de Intendentes del Río de la Plata de 1782 relativas a la labor de los subdelegados. En un ámbito donde se contaba con algunos problemas para acceder a la información o a la legislación era una manera práctica de hacerles llegar a los subdelegados sus competencias y normas para proceder en su gobierno.

La importancia de conocer estas disposiciones nos parecen muy adecuadas para poder pasar a evaluar la importancia y consecuencias de estas reformas a nivel local y a nivel nacional. No hay duda de que estos últimos cambios en la administración y gobierno de los territorios americanos fueron decisivos en los procesos de independencia y en la organización jurisdiccional de muchas de las nuevas repúblicas americanas.

\section{Archivo General de Indias, Audiencia de Charcas, Legajo 438}

El Gobernador Intendente de Potosí acompaña copia de la instrucción metódica que arreglada al espíritu de la Real Ordenanza ha remitido a los cinco subdelegados de su jurisdicción.

Muy venerado Sr. mío: Después que tomé posesión en el primer día del presente año del Gobierno e Intendencia de esta villa de Potosí y su provincia, que se sirvió conferirme la piedad del Rey y luego también que desembarazado de las primeras atenciones de este nuevo empleo pude reglar el nombramiento de subdelegados en los cinco partidos sujetos a su jurisdicción para que estos tuvieren una regla que les guiase al acierto en sus determinaciones me dediqué a formar y les he remitido la instrucción metódica arreglada al espíritu de la Real Ordenanza de que acompaño a V.E. una fiel copia con el anhelo de que ella merezca su superior aprobación.

Vuestro Sr. guarde la vida de V.E. muchos felices años.

Potosí, marzo 16 de 1784.

Juan del Pino Manrique al Exmo. Sr. D. José de Gálvez
INSTRUCCIÓN METÓDICA PARA EL REGIMEN Y GOBIERNO DE LOS SUBDELEGADOS DE ESTA INTENDENCIA DE POTOSÍY Y SU PROVINCIA EN LOS PARTIDOS DE PORCO, CHAYANTA, CHICHAS, ATACAMAY LIPEZ, ARREGLADA A LA REAL ORDENANZA DE INTENDENTE DE EXERCITOY PROVINCIA DADA EN EL PARDO A 28 DE ENERO DE 1782 Y COMUNICADA A TODAS LAS INTENDENCIAS DEL VIRREINATO DE BUENOS AIRES A QUE DEBERÁN ARREGLARSE DICHOS SUBDELEGADOS PARA EL CONOCIMIENTO DE LAS CUATRO CAUSAS DE JUSTICIA, POLICIA, HACIENDA Y GUERRA.

\section{$1^{\circ}$}

Movido el Rey N. Sr. que Dios guarde del paternal amor que le merecen todos sus vasallos aún los más distantes y con el objeto de uniformar el gobierno de estas provincias y poner en buen orden felicidad y defensas sus dilatados dominios de América ha resuelto el establecimiento de ocho intendencias con sus respectivas demarcaciones y términos en el distrito del nuevo virreinato de Buenos Aires, siendo una de ellas esta de Potosí y su provincia que aunque sin mérito se ha dignado conferirme la piedad de Nuestro Augusto soberano, cuya jurisdicción se extiende a los partidos de Porco, Chayanta, Chichas, Lipez, y Atacama.

\section{$2^{\circ}$}

Debiendo ser la principal atención de estos nuevos magistrados gobernar sus pueblos y habitantes en paz y justicia, cuidar de la policía y recaudar los intereses legítimos del Erario con arreglo a las leyes y ordenanzas, velar el aumento de la agricultura, promover el comercio, excitar la industria de los pueblos, favorecer la minería y en suma procurar por todos los medios la felicidad de estos reinos, se previene nombren subdelegados en los pueblos cabecera de partido en que hubiese habido teniente de gobernador o corregidor para que actúen en las cuatro causas de Justicia, Policía, Hacienda y Guerra; y teniendo ya para poder llenar la confianza elegidos los correspondientes a los cinco partidos de mi jurisdicción, a fin de que éstos y los que en lo sucesivo nombrare según las ocurrencias puedan rectificar el desempeño de sus empleos y oficios y desempeñar con acierto el conocimiento de las cuatro causas de Justicia, Policía, Hacienda y Guerra, he acordado remitirles la presente Instrucción, 
arreglada a el espíritu de las misma Real Ordenanza de Intendentes.

\section{$3^{\circ}$}

Antes de reglar el juicio en las cuatro causas ya ha dos años y para cumplir con lo prevenido en los artículos 8, 9, 10 y 11 de la Ordenanza me informarán los subdelegados cuantas ciudades, villas lugares y pueblos hay en su respectivo partido, sus distritos y jurisdicciones, distinguiendo los que sean de españoles y los de meros indios.

\section{$4^{\circ}$}

Aquellos (esto es las ciudades, villas y lugares de españoles) se han de gobernar por los alcaldes ordinarios elegidos por el ayuntamiento donde lo hubiere y donde no por el intendente de la provincia, bien entendido, que en los pueblos donde hubiere Ayuntamiento deberán confirmar los intendentes sus respectivas elecciones, sin cuyo requisito no podrán usar los electos de sus respectivos empleos, y en los que no les hay han de hacer dichos nombramientos los mismos intendentes procedidos los correspondientes informes a cuyo efecto convendrá que en el que se pide a los subdelegados por el anterior artículo distingan en los pueblos de españoles los que tienen Ayuntamiento de los que no le hay y me informen que vecinos hay en estos de la honradez y demás circunstancias necesarias para desempeñar con acierto los empleos de Justicia.

\section{$5^{\circ}$}

El primer año en que se verifique esta providencia que será el próximo venidero de 785 se han de elegir dos alcaldes ordinarios para cada villa o lugares de españoles cada dos años de los siguientes solo se elegirá uno porque el de primer voto que se eligiere en dicho año de 85 ha de continuar también en el siguiente y después el que entrare a ser de segundo quedará de primero en el siguiente de forma que el oficio sea bienal en todos.

\section{$6^{\circ}$}

El subdelegado deberá residir en el pueblo que haya sido cabecera del partido y en que hubiere habido teniente de gobernador o corregidor con advertencia de que ni los dichos subdelegados ni los alcaldes ordinarios ni otra persona sin excepción han de poder repartir a los indios, españoles, mestizos y demás castas, efectos, frutos ni ganados alguno bajo la pena irremisible de perder su valor en beneficio de los naturales perjudicados y de pagar otro tanto a la Cámara, Juez y denunciador sustentándose el castigo en caso de reincidencia hasta la confiscación de bienes y destierro perpetuo de los delincuentes.

\section{$7^{\circ}$}

Teniendo mandado su Majestad por el artículo $7^{\circ}$ de las disposiciones de la Real Ordenanza que de cuenta de Su Real Hacienda se avíe a los naturales y demás necesitados y otras castas que no tengan medios ni proporciones para hacerlo por si mismo del hierro, aperos, mulas y otros útiles y necesarios a la industria y labranza dándoselos al fiado y a los precios fijos que por solo costo y costas se regulen dando a estas anticipaciones el nombre de Socorros y nunca el de repartimientos, me informan los subdelegados los efectos que a este fin sean necesarios en su respectivo partido, el consumo que pude haber de ellos y todo lo demás que considere oportuno a que se consigan sin perjuicio de la Real Hacienda los alivios que la piedad del Rey quiere dispensar a los naturales de estas provincias.

Si además de los pueblos cabeceras reconociese el subdelegado ser necesario establecer otro en algún pueblo del partido de meros indios lo informará a esta intendencia con las razones que militen para ello.

\section{$9^{\circ}$}

En los pueblos de indios en que hubiese habido costumbre de elegir cada año entre ellos mismos los alcaldes y demás oficios de república que les permiten las leyes y ordenanzas para su régimen puramente económico se les ha de conservar y para impedir los disturbios y alborotos que suelen originarse con motivo de estas elecciones las ha de presidir siempre el juez español o el que esté por su acuerdo o impedimento nombrare con tal que también sea español y de este modo no se podrán celebrar ni tener validación.

$10^{\circ}$

Hechas que sean estas elecciones en la forma prevenida darán cuenta de ellas el subdelegado u alcalde ordinario en informe al intendente para que las apruebe o reforme, en cuyo acto serán preferidos los que sepan el idioma castellano y mas se distinga en las recomendables aplicaciones de agricultura e industria y lo mismo se executará en la Intendencia para su confirmación que se expedirá sin llevar derechos algunos. 
$11^{\circ}$

\section{Causa de Justicia}

En ella se atendrán los subdelegados a lo dispuesto por las leyes de estos dominios que preserven las más sabias y adaptables reglas para la administración de justicia y buen gobierno de los pueblos, teniendo igual atención a lo establecido en las Leyes de Castilla a que deben atenerse en defecto de aquellas, no siendo unas y otras contrarias a lo prevenido en la Real Ordenanza a que está sujeta esta metódica instrucción advirtiéndose desde ahora que dando los subdelegados exemplo con su propia observancia han de cuidar eficazmente de que todos los demás tanto españoles como naturales respeten y guarden dichas leyes con la observancia y exactitud debidas y que en las causas de justicia y las de policía y gobierno, cuando lleguen a ser de la misma naturaleza deberán admitir las apelaciones $\mathrm{y}$ recursos que se interpongan de sus providencias para la Real Audiencia del distrito.

\section{$12^{\circ}$}

Cuidarán muy particularmente los subdelegados de establecer y que se mantengan en los pueblos de su partido la paz y buena armonía entre sus vecinos y naturales cortando oportuna y prudentemente toda parcialidad, pasión o venganza, anteponiendo su autoridad para remediar los daños que de las enemistades resultan a la causa pública y a los particulares, informando a esta intendencia lo que en particular ocurriese para proveer de remedio y disipara las inquietudes que suele ocasionar el poder abusivo de las justicias y el de otras personas que fomentan en las repúblicas las envidias, el odio y la discordia en olvido de sus conciencias y consideración a los perjuicios que son consiguientes

\section{$13^{\circ}$}

Celarán con no menos vigilancia el breve y regular despacho de las causas y negocios pendientes sin molestar a las partes con dilaciones excesos o extorsiones ni cobrarles más derechos que los debidos según arancel.

\section{$14^{\circ}$}

Cuidarán de que los comisionados lexítimos de cualquiera tribunal actúen sin comisión con el uso $\mathrm{y}$ auxilios dispuestos por derecho sin gravar a los vecinos y naturales con indebidas exacciones dietas, o salarios y pagándoles los vagajes y mantenimientos que les suministraren a los precios corrientes y justos $15^{\circ}$

Remitirán los subdelegados una razón puntual y firmadas de las justicias y ayuntamientos donde los hubiere de los propios y arbitrios que gozaren las ciudades y villas y lugares de españoles, de la conexión y origen de ellos, de las cargas perpetuas o temporales que sufren de los gastos precisos o extraordinarios a que están sujetos, de los sobrantes o faltas que resultan al fin de cada año y de la existencia, custodia y cuenta de estos caudales previniendo que serán responsables los jueces subalternos y escribanos de la exactitud de estas noticias.

\section{$16^{\circ}$}

También informarán muy por menor de los arbitrios que gozaren los pueblos si para esto tienen facultades reales, por qué motivos y en qué destino se los concedieron y si la causa subsiste o ha cesado.

\section{$17^{\circ}$}

También remitirán otra razón de los bienes de comunidad de los pueblos de indios, su concesión, origen, cargas, gastos, sobrantes o faltas del mismo modo que por lo tocante a los pueblos de españoles va prevenido en el artículo 15 de esta instrucción.

\section{$18^{\circ}$}

Para llenar el objeto de que se arregle uniformemente el gobierno manejo y distribución de todos propios y arbitrios que gozan los pueblos de españoles y de los bienes comunes de los pueblos de indios según lo que resultare de las noticias que por los artículos anteriores se piden a los subdelegados, se formaran por esta intendencia los reglamentos prevenidos en los 27 y 28 de la Real Ordenanza y oportunamente se remitirá también a los pueblos de españoles donde hubiere ayuntamiento otro testimonio de los artículos 30 y siguientes hasta el 45 inclusive donde se previenen las reglas convenientes y que deben observados para la administración manejos, custodia y cuentas de los caudales de propios ya arbitrios.

\section{$19^{\circ}$}

Harán entender a los caciques y gobernadores de los pueblos de indios que las suplicatorias que formalicen ante el señor juez mayor de censos del distrito de la Real Audiencia de la Plata para el auxilio y socorro de las necesidades comunes, se han de dirigir en adelante a aquel juzgado por esta intendencia con informe que califique la dicha necesidad. 


\section{$20^{\circ}$}

Cuidaran de que los escribanos y notarios reales cumplan con la obligación de sus oficios y de que los protocolos y papeles de su cargo se mantengan en segura custodia evitándose toda falsedad, suplantación y omisión haciendo se observen y guarden inviolablemente las leyes y cédulas expedidas o que se expidieren sobre este punto.

\section{$21^{\circ}$}

Llevaran cuenta exacta de las penas pecuniarias o multas que se impusieren por si o por los alcaldes ordinarios de los pueblos de su partido pertenecientes a la Real Cámara o a la causa pública y sin ocultarlas ni mal versarlas la darán anualmente instruida a esta intendencia para los fines indicados en el artículo 52 de la Real Ordenanza.

\section{$22^{\circ}$}

\section{Causa de Policía}

A la administración de justicia debe unirse el cuidado de la policía y para facilitar el debido conocimiento de esta provincia, dispondrán los subdelegados un mapa topográfico de su respectivo partido en que se señalen y distingan sus pueblos, términos, montañas, bosques, Ríos y lagunas en la exactitud puntualidad y distinción posibles.

\section{$23^{\circ}$}

Informarán separadamente del temperamento y calidades de la tierra que comprehende, de sus producciones naturales en los tres reynos mineral, vegetal y animal de la industria y comercio activo con todas las particularidades convenientes a promover su felicidad y conveniencia.

\section{$24^{\circ}$}

Informarán acerca de las inclinaciones, vidas y costumbres de sus moradores para corregir y castigar a los vagos, ociosos y mal entretenidos que son perjudiciales a la República, sin que por esto se entienda que puedan entrometerse a examinar las costumbres domésticas y privadas que no ceden en perjuicio del buen exemplo ni alteren el orden de la sociedad y gobierno público.

\section{$25^{\circ}$}

Por consecuencia de lo dicho en el artículo anterior cuidarán de que en los pueblos de su partido no se consienta gente vagabunda sin destino ni aplicación al trabajo y con razón de ellos informarán a esta intendencia para proveer su justa aplicación.

\section{$26^{\circ}$}

Celarán que todos los vecinos y naturales siembren y cultiven las tierras que les están repartidas y poseen con título sin abandonarlas ni inutilizarlas con su desidia.

\section{$27^{\circ}$}

Han de procurar con toda atención que los hacendados y naturales aumenten la agricultura y siembra de granos, especialmente la de trigo aprovechando las aguas corrientes y subterráneas para el riego y fertilidad de todas las tierras que los labradores según sus facultades, tengan ganado vacuno y lanar a beneficio de sus haciendas aplicándose a la cría de mulas, caballar y al aumento de vacunos.

\section{$28^{\circ}$}

Procurarán fomentar no sólo las cosechas de cera de abejas silvestres y de colmena sino la de algodón en los países que puedan darse en inteligencia de que a este género el de la lana burda y fina labrada y el cáñamo y lino en cerro o hilados tiene SM. concedida absoluta libertad de derechos en su salida de los puertos de América entrada en los de España.

\section{$29^{\circ}$}

Cuidarán con todo esmero de tener bien reparados los puentes y compuestos los caminos públicos sin permitir a los labradores se introduzcan en ellos poniendo sus itos y mojones, castigando a los contraventores con las multas correspondientes además de obligar a reparar el daño dando cuenta con la necesaria justificación de los caminos que necesitaren mayor ensanchen, puentes, calzadas, a fin de proveer lo conveniente

\section{$30^{\circ}$}

Para la mayor comodidad de los pasajeros harán poner en todos los sitios donde se junten dos o más caminos o sendas un madero levantado y fixo con su tarjeta que diga Camino para tal lugar.

\section{$31^{\circ}$}

Cuidarán de que en todos los pueblos y parajes de tránsito y venta que se encuentre suficiente capacidad con competente provisión de víveres, camas limpias y lo demás preciso al buen hospedaje, asistencia y 
alivio de los caminantes a la menor costa posible y de modo que sin considerable gravamen de ello puedan los posaderos satisfacerse de su cuidado gasto y adelantamiento en la provisión.

\section{$32^{\circ}$}

Los subdelegados por si mismos y por los alcaldes provinciales o de la hermandad y su cuadrilleros donde los hubiere por los jueces de sus pueblos, cumplirán exactamente la obligación reconocer los campos y montes para tener en seguridad los caminos y el comercio de los pasajeros bajo de las penas impuestas en las leyes y la responsabilidad de que cualquier insulto o robo que se cometa en su distrito no procediendo con la vigilancia debida a la común seguridad.

\section{$33^{\circ}$}

Procurarán en la forma posible la limpieza, ornato, igualdad y empedrados de las calles de sus pueblos sin permitir en las fábricas que se hicieren de mucha desproporción que desfigure el aspecto público, especialmente en las ciudades y villas populosas de españoles, y si algún edificio o casa particulares amenazaren ruina obligaran a sus dueños a repararlas en el término correspondiente y de no hacerlo lo mandarán a executar a costa de los mismos procurando también que cuando se hagan obras públicas, casa nuevas de particulares o se derriben las antiguas queden las calles anchas y derechas y las plazuelas con la posible capacidad, disponiendo así mismo que si los propietarios no las reedificaren, se les obligue a vender sus solares con justa tasación para que los compradores lo executen y que en las pertenecientes a mayorazgos, capellanías o otras fundaciones se deposite judicialmente su importe hasta nueva imposición.

\section{$34^{\circ}$}

En los pueblos de indios cuidarán de que fabriquen estos sus casas en buen orden y de que mantengan reparadas las reales donde las hubiere las de comunidad y demás edificios públicos.

\section{$35^{\circ}$}

Celarán que en ningún pueblo de los de su partido se construyan iglesia ni otro edificio público sin noticia de esta intendencia y sin que previamente se remitan a ella los dibujos de sus planes, aliados y cortes para que se provea con arreglo a lo prevenido en el artículo 66 de la Real Ordenanza.

\section{$36^{\circ}$}

Cada cuatro meses me darán noticias de la escasez o abundancia de frutos de su partido y de sus respectivos precios corrientes para dar la cuenta prevenida en el artículo 67 a los señores Virrey e Intendente general de exército de la capital de Buenos Aires.

\section{$37^{\circ}$}

Tendrán mucho cuidado y atención que no se corten ni falsifiquen las monedas de oro y plata corrientes ni se vicien estos metales dando cuenta de cualquier defecto que se advirtiere en cualquier persona de la condición y estado que fuere a esta Intendencia para proveer de remedio.

\section{$38^{\circ}$}

\section{Causa de Hacienda}

En ella deberán tener entendido que la dirección de Rentas Reales establecidas de esta Provincia y la de cuantos derechos pertenezcan al Real Erario, deben correr bajo mi privativa inspección y conocimiento y que la jurisdicción contenciosa concebida antes por las leyes a los oficiales reales para la cobranza del real Haber se halla resumida y trasladada a los intendentes en sus respectivas provincias con absoluta inhibición de aquellos ministros de Real Hacienda (que quedan en este título para en lo sucesivo y con solo el veto y exercicio de sus facultades económicas y coactivas conducentes a la administración y recaudación de lo correspondiente a la Hacienda Real) han de observar los subdelegados las reglas que se siguen.

\section{$39^{\circ}$}

Sus facultades por lo respectivo a esta causa solo son extensivas a poner en estado de sentencia las que formen o se las pasen en sumaria por que las quiera dependientes de Rentas pues en dicho estado de sentencia las han de remitir a esta Intendencia para que con acuerdo de mi Teniente Asesor pronuncie la que corresponde en Justicia.

\section{$40^{\circ}$}

Con el exercicio de la Jurisdicción contenciosa en los expedientes y negocios de Rentas y su conocimiento es privativo a los Intendentes con absoluta inhibición de todos los magistrados, tribunales y Audiencias de este virreinato aceptación solo de la Junta Superior de Real Hacienda establecida en la capital de Buenos Aires, no admitirán recurso alguno 
a otro tribunal que pueda intentar la malicia de los culpados y delincuentes. Y siendo la Jurisdicción de los subdelegados para solo substanciar los negocios ocurrentes en esta causa, darán cuenta y consultarán a esta Intendencia interrumpidamente cuando se les ofrezca duda o dificultad alguna considerable.

\section{$41^{\circ}$}

Para substanciar las causas de fraudes que se hicieren contra las rentas de Tabacos y Naipes y demás pertenecientes a la Real Hacienda, observaran puntualmente las reglas prefinidas en las particulares Ordenanzas, o instrucciones de cada ramo.

\section{$42^{\circ}$}

Harán saber por bando que en esta Intendencia ha recaído y reside la jurisdicción privativa para conocer de las dependencias y causas que ocurrieren en el distrito de su provincias sobre rentas, composiciones y repartimientos de tierras realengas y de señoríos y que en su consecuencia los poseedores y los que pretendan mudar deben deducir sus derechos y formalizar sus solicitudes ante mí para substanciarlas y determinarlas conforme a derecho con dictamen de mi asesor, salvo la apelación a la Junta Superior de Hacienda y la cuenta que se le debe dar con los autos originales en estado de despachar el juicio.

\section{$43^{\circ}$}

La cobranza, conducción y entero de los Reales Tributos en las Casa principales de esta Intendencia es de precisa obligación, cuenta y riesgo de los subdelegados en cada partido, que deben hacer los enteros por medios años, según su práctica en la tesorería y el cobro del que montare esta contribución han de executarlo por mano de los respectivos gobernadores o alcaldes de los naturales obligados a su exacción y a la entrega de su importe también por medios años a los subdelegados.

$44^{\circ}$

Por el cobro, conducción y entero de los tributos que los subdelegados están obligados a hacer con arreglo a las matriculas o p0adrones y tasas que para ello se les dieren se les ha de abonar el premio del cuatro por ciento del total que enterasen en la tesorería, bien entendidos de que el uno han de dejar a los gobernadores o exactores del tributo y los tres restantes a su beneficio por la responsabilidad y trabajo en el traslado de la cobranza. $45^{\circ}$

Los gobernadores y demás alcaldes exactores del tributo solo están obligados a hacer los enteros en el pueblo cabecera residencia del subdelegado y los indios contribuyentes cumplen cn pagar su cuota en su respectivo pueblo.

\section{$46^{\circ}$}

Los enteros de tributos, los executarán íntegros en esta tesorería principal sin otro descuento que lo que importare el cuatro por ciento señalado por la cobranza, quedando cortada la práctica de satisfacerse los sínodos de curas, párrocos y por los justicias que recaudaban el real tributo del territorio, cuya data no se les admitirá, por deberse hacer estas satisfacciones en la misma tesorería a los curas no a sus apoderados, íntegramente y sin demora.

\section{$47^{\circ}$}

Para precaver los fraudes corruptos algunas personas por eximirse de las justa contribución de alcabalas, ceden tonar o traspasar dolosamente sus posesiones en hijos y parientes eclesiásticos contraviniendo a lo dispuesto por las leyes, harán saber a los escribanos o notarios residentes en sus partidos que bajo la pena que impone la ley $3^{\circ}$, titulo 13, libro 8 de la Recopilación de Yndias no puedan extender instrumentos de estas cesiones, donaciones o traspasos aunque sean en el nombre de ventas sin que preceda expresa licencia y facultad de esta Intendencia y sus respectivos subdelegados, quienes para concederla deberá representarme previamente con el respectivo informe.

\section{$48^{\circ}$}

Informarán por cómputo prudencial el consumo y expendio del papel sellado en su partido para proveer el envío de la porción necesarias.

\section{$49^{\circ}$}

Siendo muy conveniente y conforme a las intenciones Reales el fomento y protección del cuerpo de Minería para animar su industria y adelantar su utilísima profesión celarán los subdelegados no se haga agravio extorción ni violencia a los que se emplearen en el descubrimiento, labor y beneficio de minas, que los operarios de ellas no consientan robos o excesos contra sus dueños, ni estos tiranicen o perjudiquen a aquellos con aumentarles las faenas, o minorarles los jornales o salarios según 
sus ocupaciones o convenios que se hubieran hecho y que sus negocios y expedientes se prefieran para su breve despacho, observándose puntualmente las ordenanzas del asunto y las leyes del título 19 , libro $4^{\circ}$ de las de estos dominios.

\section{$50^{\circ}$}

\section{Causa de Guerra}

Como todo el conocimiento que deben tener los intendentes en esta causa es sólo contraídas a los dos puntos de suministrar su haber en dinero a las tropas y su manutención en víveres, se arreglaran los subdelegados a las órdenes que oportunamente se les comunicarán por esta Intendencia, cuando hubieren de transitar tropas por su partido o hacer alguna misión en ellos.

\section{$51^{\circ}$}

Por último se advierte que en todos los asuntos que para llevar los 51 artículos de esta instrucción y más particularmente en los informes que se piden por $\operatorname{los} 3^{\circ}, 4^{\circ}, 7^{\circ}, 8^{\circ}, 15^{\circ}, 16^{\circ}, 17^{\circ}, 22^{\circ}, 23^{\circ}, 24^{\circ} \mathrm{y}$ $36^{\circ}$ como en todos los demás puntos que por razón de sus oficios deben tratar dichos subdelegados con esta Intendencia, nunca han de exponer en cada informe más que un asunto para evitar la confusión que resulta de tratar en cada papel os o más puntos que deben llevarse con separación y pertenecen a diversos expedientes.

\section{Potosí y Enero 28 de 1784 \\ Juan del Pino Manrique}

\section{Referencias Citadas}

Acevedo, E.O.

1992 Las intendencias altoperuanas en el virreinato del Río de la Plata. Academia de la Historia, Buenos Aires.

Brading, D.

1975 Mineros y comerciantes en el México borbónico (17631810), Fondo de Cultura Económica. México

Buechler, R.M

1989 Gobierno, minería y sociedad. Potosí y el Renacimiento borbónico 1776-1810, Biblioteca Minera Boliviana, La Paz.

De Angelis, P.

1836 "Discurso preliminar a la Descripción de Potosí", Buenos Aires, 12 de abril de 1836. www.cervantesvirtual.com

Del Pino Manrique, J.

Descripción de la villa de Potosí y de los partidos sujetos a su intendencia. www.cervantesvirtual.com

Gavira, M.C.

2008 Población indígena, sublevación y minería en Carangas, Universidad de Tarapacá e Instituto Francés de Estudios Andinos, Arica.

Golte J.

1980 Repartosy Rebeliones, Instituto de Estudios Peruanos, Lima.

Lewin, B.

1957 La Rebelión de Tupac Amaru y los orígenes de la emancipación americana, Ed. Hachette, Buenos Aires,

Luque Talaván, M.

1999 "La Intendencia de Puno: de circunscripción colonial a departamento de la República del Perú (1784-1824)”, en Revista Complutense de Historia de América, 25: 219-252, Madrid.

Lynch, J.

1962 Administración colonial española. El sistema de intendencias en el virreinato del Río de la Plata, Editorial Universitaria, Buenos Aires

Mantilla M., Diego-Fernández R., Y. Moreno

2008 Real Ordenanza para el establecimiento e instrucción de intendentes de exército y provincia en el reino de Nueva
España. Edición anotada de la Audiencia de la Nueva Galicia (Edición y estudios), El Colegio de Michoacán, México.

Mariluz Urquijo

1987 El virreinato del Río de la Plata en la época del Marqués de Avilés: 1799-1801. Plus Ultra, Buenos Aires.

1995 "La causa de hacienda", en Estudios sobre la Real Ordenanza de Intendentes del Río de la Plata, Instituto de Investigaciones de Historia del Derecho, Buenos Aires.

Maritire, E.

2005 La Audiencias y la Administración de Justicia de las Indias. Madrid, Universidad Autónoma de Madrid.

Moreno Cebrian, A.

1979 El corregidor de indios y la economía peruana en el siglo XVIII, Instituto Fernández de Oviedo, CSIC. Madrid.

Ravignani, E.

1938 "El virreinato del Río de la Plata. Su formación histórica e institucional", en Historia de la Nación Argentina, T. IV Colección dirigida por Ricardo Levene, Buenos Aires.

2005 La Audiencias y la Administración de Justicia de las Indias, Universidad Autónoma de Madrid, Madrid.

Rees Jone, R.

1992 El superintendente Manuel Ignacio Fernández (17781783): las reformas Borbónicas en el virreinato de Buenos Aires, Instituto de Investigaciones de Historia del Derecho, Buenos Aires.

1995 “La Ordenanza General de Intendentes de 1803”, en Estudios sobre la Real Ordenanza de Intendentes del Río de la Plata, Buenos Aires.

San Martino, L.

1999 Constitución indiana de Carlos III. La Real Ordenanza de Intendentes de 1782, Buenos Aires.

Tandeter, E.

1992 Coacción y mercado. La minería de la plata en el Potosí colonial, 1692-1826, Editorial Sudamericana, Buenos Aires. 


\section{Notas}

1 Un ejemplo concreto al que se refiere el autor es que en las Ordenanzas del Río de la Plata no se hace alusión al estímulo de la industria, mientras que es una de las disposiciones de las Ordenanzas de 1749 destinadas a las Intendencias de la Península.

2 Según el estudio de Laura San Martino (1999) pág. 24, estas normas proceden de las consultas con distintas autoridades del virreinato para ajustar las ordenanzas a la realidad y que el resultado fue aceptado por Gálvez y Carlos III, e incorporados por Real Cedula.

3 El partido de Tarija fue creado en 1785 separándose del partido de Chichas con capital en la villa de San Bernardo de Tarija. Posteriormente una Real Cedula de 1807 separaba el partido de Tarija, de Chichas y el Chaco para integrarlo a la Intendencia de Salta del Tucumán.

4 Estas condiciones diferentes dieron lugar a muchos conflictos por competencias entre los subdelegados y otras instituciones. En Nueva España igualmente se establecieron dos subdelegados diferentes, de dos o cuatro causas, y también se generaron muchos conflictos. Véase Brading (1975) págs. $112-114$.

5 Le daba prioridad a Chayanta -decía el intendente-porque la magnitud de sus tributos así lo requería, además de considerar que el mineral de Aullagas necesitaba de su presencia para evitar extravíos de platas y cortar los partidos que se gestaban entre los mineros.
6 Archivo General de Indias, Charcas, 438, N 155. Potosí, 16 de junio de 1787.

7 www. Cervantesvirtual.com. Juan del Pino Manrique, Descripción de la villa de Potosí y de los partidos sujetos a su intendencia.

8 Artículo 132. Véase Real Ordenanza para el establecimiento e instrucción de intendentes de exército y provincia en el reino de Nueva España. Edición anotada de la Audiencia de la Nueva Galicia (Edición y estudios de Mantilla M.; Diego-Fernández R.; y Moreno A. México, 2008, pág. 287.

9 Archivo General de Indias, Charcas, 694. Hoja de servicio de Don Pedro Francisco de Arismendi, fechada 31 de mayo de 1797.

10 Archivo Nacional de Bolivia, Minas, T. 79, N ${ }^{\circ} 6$. Francisco de Basagoitia al Intendente Francisco de Paula Sanz, Potosí, 18 de febrero de 1799 .

11 Sobre la figura del Corregidor en el virreinato peruano véase Moreno Cebrián, (1979).

12 Golte relaciona, en un trabajo clásico, los abusos en los repartos de mercancías y los focos de los levantamientos indígenas.

13 Archivo Histórico Nacional, Madrid. Consejos 20366, Exp. 1.

14 Este fue el caso Juan Dionisio Marín, Corregidor de Carangas. Véase Gavira, M.C. (2008). 